\title{
Determinants of Cesarean Section Deliveries in Public Hospitals of Addis Ababa, Ethiopia, 2018/19: A Case-Control Study
}

\author{
Areaya Gebreegziabher Hailu, ${ }^{1}$ Tsegaye Kebede Fanta, ${ }^{1}$ Fissaha Tekulu Welay ${ }^{(D)}{ }^{2}$ \\ Natnael Etsay Assefa $\left(\mathbb{D},{ }^{2}\right.$ Surafel Aregawi Hadera, ${ }^{3}$ Gebrekiros Aregawi Gebremeskel, ${ }^{3}$ \\ Hagos Weldeslassie Gebremedhin, ${ }^{4}$ and Guesh Gebreayezgi Asefa ${ }^{5}{ }^{5}$ \\ ${ }^{1}$ Department of Public Health, Gamby Medical and Business College, Bahir Dar, Ethiopia \\ ${ }^{2}$ Department of Midwifery, Adigrat University, Adigrat, Ethiopia \\ ${ }^{3}$ Department of Midwifery, Aksum University, Axum, Ethiopia \\ ${ }^{4}$ Department of Reproductive Health, Sante Medical College, Addis Ababa, Ethiopia \\ ${ }^{5}$ Department of Epidemiology and Biostatistics, School of Public Health, Akum University, Axum, Ethiopia
}

Correspondence should be addressed to Guesh Gebreayezgi Asefa; gumawi960@gmail.com

Received 5 December 2019; Revised 22 March 2020; Accepted 30 March 2020; Published 20 April 2020

Academic Editor: Curt W. Burger

Copyright (c) 2020 Areaya Gebreegziabher Hailu et al. This is an open access article distributed under the Creative Commons Attribution License, which permits unrestricted use, distribution, and reproduction in any medium, provided the original work is properly cited.

\begin{abstract}
Objective. The objective of this study was to assess the determinants of cesarean section deliveries in public hospitals of Addis Ababa, Ethiopia, 2019. Method. A hospital-based unmatched case-control study was conducted to study 780 (260 cases and 520 controls) women who delivered in public hospitals of Addis Ababa from August 22 to September 20, 2019. The cases were all mothers who delivered through caesarean section, and controls were all mothers who delivered vaginally in the same time in the study area. Data were collected from the randomly selected women and looking into their cards. Data were entered on EpiData 3.1 and exported to SPSS version 20 for cleaning and analyzing. Binary logistic regression and AOR with 95\% CI were used to assess the determinants of caesarean section. Results. Majority of the study participants were in the age category 20-34 years. Nearly more than $1 / 3^{\text {rd }}$ of the participants $(32.7 \%$ cases and $34.6 \%$ controls) have attended primary school. Most of the cases 217 (83.5\%) and few of the controls 21 (4\%) possess previous caesarean section. One hundred three (52.3\%) of the cases and 329 (63.6\%) controls were multi-parous. Previous caesarean delivery $(\mathrm{AOR}=6.93,95 \% \mathrm{CI} ;(3.39,14.16))$, singleton pregnancy $(\mathrm{AOR}=0.34$, $95 \% \mathrm{CI} ;(0.12,0.83))$, birth weight less than $2500 \mathrm{gm}(\mathrm{AOR}=0.29,95 \% \mathrm{CI} ;(0.18,0.92))$, birth weight greater than 4000 gm $(\mathrm{AOR}=16.15(8.22,31.74))$, completely documented partograph $(\mathrm{AOR}=0.13,95 \% \mathrm{CI} ;(0.078,0.23))$, and pregnancy-induced hypertension $(\mathrm{AOR}=2.44,95 \% \mathrm{CI} ;(1.46,4.08))$ were significant determinants of caesarean delivery in this study. Conclusion. Previous caesarean section, number of delivery, birth weight, partograph documentation, and pregnancy-induced hypertension had significant association with caesarean section delivery in this study.
\end{abstract}

\section{Introduction}

The proportion of caesarean section (CS) to the total births is considered as one of the important indicators of emergency obstetric care [1]. Currently, the WHO states that CS has paramount importance on reducing maternal and perinatal mortality and morbidity, provided that there is justified medical indication. However, in the absence of clear medical justification, CS has no medical benefit, rather it is associated with short- and long-term health risks as compared with vaginal delivery [2].

CS rates have been rising progressively worldwide with a wide variation between countries and regions. It is globally known that CS delivery can present several risks than a vaginal birth even if it has become nowadays one of obstetric intensive cares regarding its benefits for mother and baby [3].

Many studies indicated medical and nonmedical factors that are likely to be associated with the rising rate of CS 
which include social and obstetric maternal factors (age, educational status, income, preference, height, weight, parity, premature rupture of the amniotic fluid membrane, and multiple pregnancy), fetal factors (macrosomia, breech presentation, etc.), and indications (cephalopelvic disproportion, hypertensive disorders of pregnancy, antepartum hemorrhage, previous caesarean section, and fetal distress) [4-10].

Though the rate of CS is increasing in a normal pregnancy, CS has eight-fold higher maternal mortality and 8-12 times higher morbidity than vaginal delivery [11, 12]. Nowadays, the CS rate has become more prevalent without a clear medical justification though it is associated with an increased morbidity and mortality of mothers and children [13-17].

In 2015, the WHO suggested CS can save the life of the mother and infant as well only when it is medically justified [2]. The Ethiopian Demographic Health Survey (EDHS) 2016 reported over utilization of CS rates in Addis Ababa $(21.4 \%)$ [18]. However, there is uncertainty if the determinants leading to CS delivery are up to the WHO recommendation. Thus, this study is intended to determine what factors are really predisposing mothers to CS delivery. Moreover, this study would help to have an extensive and up-to-date picture on the problem.

\section{Main Text}

2.1. Methods. A quantitative facility-based unmatched casecontrol study design was applied to study a total of 780 participant mothers from August 22 to September 20, 2019. The mothers were interviewed after they gave birth either by spontaneous vaginal delivery or caesarean section. Mothers who delivered a baby after fetal viability ( 28 weeks) were included, while those who were admitted to the postnatal ward after home delivery were excluded from this study. The sample size was calculated using Epi Info version 3.5.1 statistical software using the double population formula for the unmatched case-control study. Hence, considering the previous exposure of macrosomia baby $(p 1=52 \%$ for cases and $p 2=1.6 \%)$ and $10 \%$ nonresponse rate, the calculated value was 260 for cases and 520 for controls. Finally, the total number of samples was 780 mothers. The study was conducted on six public hospitals administered by Addis Ababa Health Bureau. Thus, the sample size was allocated proportionally based on the average delivery load in the past three months (February, March, and April). Cases and controls were selected exclusively using the systematic random sampling technique. The data were collected using a questionnaire and checklist. The questionnaire was structured, pretested, translated, and adapted from previous articles. Medical records of parturient mothers were used to extract information such as partograph, gestational age at delivery, fetal presentation, indication of CS, and birth weight of the fetus, while the information of the other variables were primary data taken from interview of postnatal mothers.

The data for this study were collected after ethical clearance was obtained from Gamby Medical and Business
College and Addis Ababa public health research and emergency management care process. The participants were informed about the objective clearly and were also informed that the information they provided is only used for research purposes and kept confidential. Finally, the collected data were entered on EpiData3.1 and exported to SPSS version 20 for analysis. The variables with $p<0.25$ on bivariate logistic regression were taken to multivariable logistic regression to control possible confounding factors. Finally, adjusted odds ratio with $95 \%$ confidence interval was used to measure strength of association between the predictors and occurrence of CS. Statistical significance was declared at $p<0.05$.

Cases are mothers who delivered by caesarean section, whereas controls are those who delivered vaginally.

In this study, complete and partial partograph documentation is defined as if all the component of partograph was correctly filled and some components were missed, respectively, at the time of reviewing mother's card. Meanwhile, partograph is reported as undocumented if and only if the labor was not followed by Partograph at all.

Prolonged premature rupture of membrane is defined as duration of rupture of the membrane greater than 12 hours before the onset of labor [19].

Duration of labor: the duration of labor in this study is measured from the onset of true labor including the latent phase of first stage of labor to third stage of labor.

\section{Result}

3.1. Socioeconomic and Demographic Characteristics. The study recruited 780 mothers (260 cases and 520 controls) making a response rate of $100 \%$. Majority of the participants (82.3\% cases and $86 \%$ controls) were in the age category of 20-34 years. Nearly one third of enrolled mothers $(32.7 \%$ cases and $34.6 \%$ controls) have attended primary school (Table 1).

3.2. Obstetric Characteristics of the Participants. More than half of cases and nearly $2 / 3^{\text {rd }}$ of controls were multi-parous. Twenty-seven (10.4\%) of cases and fifty (9.6\%) of controls had previous stillbirth. Eighty-nine $(34.2 \%)$ of cases and fifty-two (10\%) of controls had faced fetal distress during labor. Most $(83.5 \%)$ of the cases and $4 \%$ of controls had previous CS delivery (Table 2).

Fully documented partograph was higher in controls than cases, whereas more proportion of partially and not documented partograph was higher in cases than controls (Figure 1).

In Table 3, the Robson classification is used to compare the risk of delivering via CS among the ten groups of the delivering women. In this study, $2 / 3^{\text {rd }}(67.4 \%)$ of group five and more than half of group eight $(54.5 \%)$ and group two (51.5\%) of the Robson classification were delivered through CS delivery (Table 3).

3.3. Determinants of Caesarean Section Deliveries. Women who had previous CS and had completely documented partograph $(\mathrm{AOR}=6.93,95 \% \mathrm{CI} ;(3.39,14.16)$ and 
TABLE 1: Socioeconomic and demographic characteristics of cases and controls in public hospitals of Addis Ababa, Ethiopia, 2019.

\begin{tabular}{|c|c|c|c|}
\hline Variable & Category & $\begin{array}{c}\text { Case } \\
\text { No }(\%)\end{array}$ & $\begin{array}{l}\text { Control } \\
\text { No }(\%)\end{array}$ \\
\hline \multirow{3}{*}{ Age (years) } & $15-19$ & $3(1.2)$ & $17(3.2)$ \\
\hline & $20-34$ & $214(82.3)$ & $447(86)$ \\
\hline & $\geq 35$ & $43(16.5)$ & $56(10.8)$ \\
\hline \multirow{4}{*}{ Marital status } & Married & $242(93.1)$ & $454(87.2)$ \\
\hline & Single & $14(5.4)$ & $45(8.7)$ \\
\hline & Divorced & $3(1.1)$ & $17(3.3)$ \\
\hline & Widowed & $1(0.4)$ & $4(0.8)$ \\
\hline \multirow{4}{*}{ Educational status } & Not able to read and write & $43(16.5)$ & $78(15)$ \\
\hline & Grade $1-8$ & $85(32.7)$ & $180(34.6)$ \\
\hline & Grade 9-12 & $66(25.4)$ & $130(25)$ \\
\hline & College and above & $66(25.4)$ & $132(25.4)$ \\
\hline \multirow{5}{*}{ Occupational status } & House wife & $118(45.4)$ & $229(44)$ \\
\hline & Merchant & $44(16.9)$ & $77(14.8)$ \\
\hline & Government employed & $48(18.5)$ & $89(17.1)$ \\
\hline & Private employed & $44(16.9)$ & $108(20.8)$ \\
\hline & Student & $6(2.3)$ & $17(3.3)$ \\
\hline \multirow{4}{*}{ Monthly income } & $\leq 1000$ & $37(14.2)$ & $82(15.8)$ \\
\hline & $1001-2500$ & $54(20.8)$ & $131(25.2)$ \\
\hline & 2501-3999 & $43(16.5)$ & $132(25.4)$ \\
\hline & $\geq 4000$ & $126(48.5)$ & $175(33.6)$ \\
\hline
\end{tabular}

TABle 2: Obstetric characteristics of the participants of the study in public hospitals of Addis Ababa, Ethiopia, 2019.

\begin{tabular}{|c|c|c|c|}
\hline Variable & Category & $\begin{array}{c}\text { Case } \\
\text { No }(\%) \\
\end{array}$ & $\begin{array}{l}\text { Control } \\
\text { No }(\%) \\
\end{array}$ \\
\hline \multirow{3}{*}{ Parity } & Primipara & $114(38.8)$ & $180(61.2)$ \\
\hline & Multipara with no previous CS & $103(24.4)$ & $319(75.6)$ \\
\hline & Multipara with previous CS & $43(67.2)$ & $21(32.8)$ \\
\hline \multirow{2}{*}{ Previous stillbirth } & Yes & $27(10.4)$ & $50(9.6)$ \\
\hline & No & $233(89.6)$ & $470(90.4)$ \\
\hline \multirow{2}{*}{ Previous abortion } & Yes & $84(32.3)$ & $118(22.7)$ \\
\hline & No & $176(67.7)$ & $402(77.3)$ \\
\hline \multirow{2}{*}{ Labor onset } & Spontaneous & $154(59.2)$ & $372(71.5)$ \\
\hline & Induced & $106(40.8)$ & $148(28.5)$ \\
\hline \multirow{2}{*}{ ANC follow-up } & Yes & $246(94.6)$ & $502(96.5)$ \\
\hline & No & $14(5.4)$ & $18(3.5)$ \\
\hline \multirow{4}{*}{ Number of ANC visit } & $1^{\text {st }}$ visit & $9(3.7)$ & $7(1.4)$ \\
\hline & $2^{\text {nd }}$ visit & $21(8.5)$ & $21(4.2)$ \\
\hline & $3^{\text {rd }}$ visit & $44(17.9)$ & $86(17.1)$ \\
\hline & $4^{\text {th }}$ visit & $172(69.9)$ & $388(77.3)$ \\
\hline \multirow{2}{*}{ Emergency referral in } & Yes & $101(38.8)$ & $153(29.4)$ \\
\hline & No & $159(61.2)$ & $367(70.6)$ \\
\hline \multirow{2}{*}{ Twin pregnancy } & Yes & $12(4.6)$ & $10(1.9)$ \\
\hline & No & $248(95.4)$ & $510(98.1)$ \\
\hline \multirow{3}{*}{ Gestational age (weeks) } & $<37$ & $8(3.1)$ & $41(7.9)$ \\
\hline & $37-42$ & $239(91.9)$ & $468(90)$ \\
\hline & $>42$ & $13(5)$ & $11(2.1)$ \\
\hline \multirow{3}{*}{ Fetal presentation at delivery } & Cephalic & $217(83.5)$ & $466(89.6)$ \\
\hline & Breech & $36(13.8)$ & $47(9.1)$ \\
\hline & Transverse/oblique & $7(2.7)$ & $7(1.3)$ \\
\hline \multirow{2}{*}{ Prolonged premature rupture of membrane } & Yes & $78(30)$ & $132(25.4)$ \\
\hline & No & $182(70)$ & $388(74.6)$ \\
\hline \multirow{3}{*}{ Neonatal birth weight (gm) } & $<2500$ & $28(10.8)$ & $126(24.2)$ \\
\hline & 2500 to 4000 & $188(72.3)$ & $386(74.2)$ \\
\hline & $>4000$ & $44(16.9)$ & $8(1.6)$ \\
\hline \multirow{2}{*}{ Duration of labor (hours) } & $\leq 24$ & $212(81.5)$ & $482(92.7)$ \\
\hline & $>24$ & $48(18.5)$ & $38(7.3)$ \\
\hline
\end{tabular}


TABle 2: Continued.

\begin{tabular}{|c|c|c|c|}
\hline Variable & Category & $\begin{array}{c}\text { Case } \\
\text { No (\%) }\end{array}$ & $\begin{array}{l}\text { Control } \\
\text { No (\%) }\end{array}$ \\
\hline \multirow{2}{*}{ Previous CS } & Yes & $217(83.5)$ & $21(4)$ \\
\hline & No & $43(16.5)$ & $499(96)$ \\
\hline \multirow{2}{*}{ Fetal distress } & Yes & $89(34.2)$ & $52(10)$ \\
\hline & No & $171(65.8)$ & $468(90)$ \\
\hline \multirow{2}{*}{$\mathrm{APH}$} & Yes & $14(5.4)$ & $4(0.8)$ \\
\hline & No & $246(94.6)$ & $516(99.2)$ \\
\hline \multirow{2}{*}{$\mathrm{PIH}$} & Yes & $69(26.5)$ & $68(13.1)$ \\
\hline & No & $191(73.5)$ & $452(86.9)$ \\
\hline
\end{tabular}

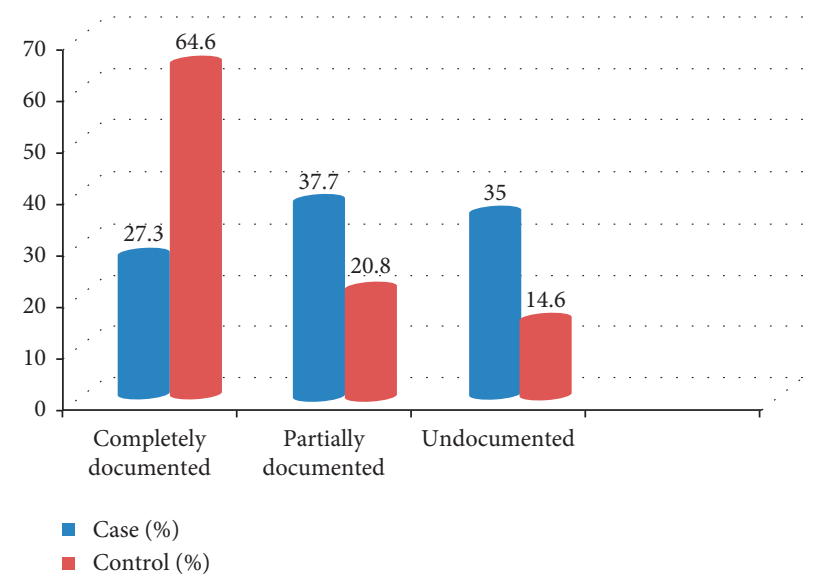

Figure 1: Bar graph showing status of partograph documentation for cases and controls among women who delivered in public hospitals of Addis Ababa, Ethiopia, 2019.

TABLE 3: Robson classification and risk of CS of the participants of the study in public hospitals of Addis Ababa, Ethiopia, 2019.

\begin{tabular}{|c|c|c|c|c|}
\hline & & & Case $(\%)$ & Control (\%) \\
\hline \multirow{10}{*}{$\begin{array}{l}\text { Robson } \\
\text { classification }\end{array}$} & Group 1 & $\begin{array}{c}\text { Nulliparous with single cephalic pregnancy, } \geq 37 \text { weeks in } \\
\text { spontaneous labor }\end{array}$ & $34(23.9)$ & $108(76.1)$ \\
\hline & Group 2 & $\begin{array}{c}\text { Nulliparous with single cephalic } \\
\text { pregnancy, } \geq 37 \text { weeks who } \\
\text { either had induced labor or CS delivery before labor } \\
\text { Multi-parous without }\end{array}$ & $56(51.5)$ & $32(48.5)$ \\
\hline & Group 3 & $\begin{array}{l}\text { previous uterine scar, single cephalic pregnancy, } \geq 37 \text { weeks in } \\
\text { spontaneous labor }\end{array}$ & $51(22.0)$ & $181(78.0)$ \\
\hline & Group 4 & $\begin{array}{c}\text { Multi-parous without previous uterine scar, with single cephalic } \\
\text { pregnancy, } \geq 37 \text { weeks who either had } \\
\text { induced labor or CS delivery before labor }\end{array}$ & $23(22.8)$ & $78(77.2)$ \\
\hline & Group 5 & $\begin{array}{l}\text { All multi-parous with at least on previous CS, with single cephalic } \\
\text { pregnancy, } \geq 37 \text { weeks }\end{array}$ & $31(67.4)$ & $15(32.6)$ \\
\hline & Group 6 & All nulliparous with single breech pregnancy & $10(45.5)$ & $12(54.5)$ \\
\hline & Group 7 & $\begin{array}{c}\text { All multi-parous with single breech pregnancy including previous } \\
\text { uterine scars }\end{array}$ & $25(42.4)$ & $34(57.6)$ \\
\hline & Group 8 & All multiple pregnancy including previous uterine scars & $12(54.5)$ & $10(45.5)$ \\
\hline & Group 9 & $\begin{array}{c}\text { All single pregnancy with transverse or oblique lie including } \\
\text { women with previous uterine scars }\end{array}$ & 0 & 0 \\
\hline & Group 10 & $\begin{array}{c}\text { All single cephalic pregnancy } \leq 37 \text { weeks including women with } \\
\text { previous uterine scars }\end{array}$ & $5(11.4)$ & $39(88.6)$ \\
\hline
\end{tabular}


TABLE 4: Logistic regression analysis results for determinants of CS delivery in public hospitals of Addis Ababa, Ethiopia, 2019.

\begin{tabular}{|c|c|c|c|c|c|}
\hline Variable & Category & $\begin{array}{c}\text { CS } \\
\text { No }(\%)\end{array}$ & $\begin{array}{c}\text { VD } \\
\text { No (\%) }\end{array}$ & COR (95\%) & AOR (95\%) \\
\hline \multirow{3}{*}{ Age (years) } & $15-19$ & $3(1.2)$ & $17(3.2)$ & $0.230(0.063,0.83)$ & $0.206(0.038,1.10)$ \\
\hline & $20-34$ & $214(82.3)$ & $447(86)$ & $0.623(0.40,0.95)$ & $0.69(0.47,1.13)$ \\
\hline & $\geq 35$ & $43(16.5)$ & $56(10.8)$ & 1 & 1 \\
\hline \multirow{4}{*}{ Occupational status } & House wife & $118(45.4)$ & $229(44)$ & $1.265(0.83,1.91)$ & $1.144(0.63,2.074)$ \\
\hline & Merchant & $44(16.9)$ & $77(14.8)$ & $1.403(0.84,2.34)$ & $1.476(0.73,2.98)$ \\
\hline & Government employed & $48(18.5)$ & $89(17.1)$ & $1.324(0.67,1.54)$ & $1.35(0.68,2.67)$ \\
\hline & Private employed & $44(16.9)$ & $108(20.8)$ & 1 & 1 \\
\hline \multirow{2}{*}{ Previous abortion } & Yes & $84(32.3)$ & $11822.7)$ & $1.623(1.17,2.26)$ & $0.94(0.592,1.49)$ \\
\hline & No & $176(67.7)$ & $402(77.3)$ & 1 & 1 \\
\hline \multirow{2}{*}{ ANC follow-up } & Yes & $246(94.6)$ & $502(96.5)$ & $0.63(0.31,1.29)$ & $1.93(0.316,11.82)$ \\
\hline & No & $14(5.4)$ & $18(3.5)$ & 1 & 1 \\
\hline \multirow{2}{*}{ Previous CS } & Yes & $43(16.5)$ & $21(4)$ & $4.71(2.73,8.13)$ & $6.93(3.39,14.16)^{*}$ \\
\hline & No & $217(83.5)$ & $499(96)$ & 1 & 1 \\
\hline \multirow{2}{*}{ Emergency referral } & Yes & $101(38.8)$ & $153(29.4)$ & $1.52(1.12,2.08)$ & $1.02(0.66,1.58)$ \\
\hline & No & $159(61.2)$ & $367(70.6)$ & 1 & 1 \\
\hline \multirow{2}{*}{ Pregnancy-induced hypertension } & Yes & $69(26.5)$ & $68(13.1)$ & $2.40(1.65,3.49)$ & $2.44(1.46,4.08)^{*}$ \\
\hline & No & $191(73.5)$ & $452(86.9)$ & 1 & 1 \\
\hline \multirow{2}{*}{ Twin delivery } & No & $248(95.4)$ & $510(98.1)$ & $0.40(0.17,0.95)$ & $0.34(0.12,0.83)^{*}$ \\
\hline & Yes & $12(4.6)$ & $10(1.90)$ & 1 & 1 \\
\hline \multirow{2}{*}{ Prolonged premature rupture of membrane } & Yes & $78(30)$ & $132(25.4)$ & $1.26(0.91,1.75)$ & $1.39(0.88,2.20)$ \\
\hline & No & $182(70)$ & $388(74.6)$ & 1 & 1 \\
\hline \multirow{3}{*}{ Birth weight (gm) } & $<2500$ & $28(10.8)$ & $126(24.2)$ & $0.46(0.29,0.72)$ & $0.29(0.18,0.92)^{*}$ \\
\hline & $2500-4000$ & $188(72.3)$ & $386(74.2)$ & 1 & 1 \\
\hline & $>4000$ & $44(16.9)$ & $8(1.6)$ & $11.3(5.2,24.5)$ & $16.15(8.22,31.74)^{*}$ \\
\hline \multirow{3}{*}{ Partograph documentation } & Completely documented & $71(27.3)$ & $336(64.6)$ & $0.176(0.12,0.26)$ & $0.13(0.078,0.23)^{*}$ \\
\hline & Partially documented & $98(37.7)$ & $108(20.8)$ & $0.758(0.50,1.14)$ & $0.64(0.37,1.10)$ \\
\hline & Undocumented & $91(35)$ & $76(14.6)$ & & 1 \\
\hline
\end{tabular}

$\mathrm{COR}=$ crude odds ratio, $\mathrm{AOR}=$ adjusted odds ratio ${ }^{*}$ Statistically significant at $p<0.05$.

$(\mathrm{AOR}=0.13,95 \% \mathrm{CI} ;(0.078,0.23)$, respectively, were more likely to undergo CS than their counter parts (Table 4).

\section{Discussion}

CS is a life-saving procedure. Thus, the procedure should not be done without clear medical indication. In this study, mothers who underwent previous CS were 6.93 times more likely to deliver by CS for the consecutive birth compared with those who gave birth via vaginal delivery. This finding is consistent with the studies conducted in Bahir Dar, Harar, Addis Ababa, Mekelle, and Dessie [20-24]. This might be due to the fear of uterine rupture associated with waiting longer time.

Pregnancy-induced hypertension during labor was found risky for CS delivery. Hence, it is similar with the study conducted in Bukavu Provincial Hospital in Democratic Republic of Congo [25]. The possible reason could be long duration of vaginal delivery in case of pregnancy-induced hypertension.

In this study, neonatal birth weight $\geq 4000$ gm was more likely to deliver through CS than birth weight of 2500-4000 gm. Perhaps, it is in line with the study done in eastern Ethiopia; Felege Hiwot Hospital, Oman, and DR Congo $[20,25,26]$. This is because macrosomia babies would face birth difficulty if vaginal delivery is allowed.
This study showed that completely filled partograph was $87 \%$ less likely to go to CS room than undocumented partograph. Studies conducted in Adigrat and Mekelle agreed with this study $[23,27]$. This might be due to close monitoring of partograph decreasing the likelihood of CS rate.

Furthermore, singleton pregnancy was found as a protective factor for caesarian delivery.

\subsection{Limitations of the Study}

(i) Some very important factors like maternal height and body mass index (BMI) were not included as they are not routinely registered on medical cards at the setups where the research was conducted

(ii) Scare to add qualitative part would not have given a chance for women to discuss more information about the decision-making process (attitude and perception of physicians and family)

\section{Conclusion}

In this study, only the obstetric characteristics were significant. Previous CS, number of delivery, birth weight, partograph documentation, and pregnancy-induced hypertension had significant association with CS delivery. 
Future studies need to examine the attitude of service providers and their influence on the growing CS delivery rate.

\section{Data Availability}

The datasets during and/or analyzed on the current study are available from the corresponding author on reasonable request.

\section{Ethical Approval}

Before starting the data collection process, ethical clearance was obtained from the Addis Ababa Health Bureau ethical clearance committee (tel: +251-115-51-3911, FAX: 251-11551-56-89, P.O. box: 30738, Addis Ababa, Ethiopia) to each selected hospitals.

\section{Consent}

Informed, written, and signed consent was obtained from each head of every facility involved in the study and participant mothers after the purpose and benefits of the study are discussed. Participants were informed about the minimal risk that it had in taking part in the study, their volunteerism, and the right to leave the interview at any time they want. Confidentiality of the study participant's information was also kept secure.

\section{Conflicts of Interest}

The authors declare that they have no competing interests.

\section{Authors' Contributions}

AG proposed and designed the study and developed the manuscript. TK supervised, advised, and helped in the analysis. GG assisted interpretation of the result and preparation of the draft of the manuscript. FT assisted on proposal development and the final write up of the data collection tool. NE performed the statistical analysis of the study. All authors read and approved the final manuscript.

\section{Acknowledgments}

The authors would like to thank Gamby Medical and Business College for giving a hand up on accomplishment of the study. Next, the authors express their gratitude to the respective hospitals $\mathrm{CEO}$ for providing the necessary baseline information. Last but not least, the authors would like to acknowledge data collectors, supervisor, and study participants.

\section{References}

[1] WHO, UNICEF, UNFPA, and World Bank, Trends in Maternal Mortality: 1990 to 2010, World Health Organization, Geneva, Switzerland, 2012.

[2] UNDP, UNFPA, UNICEF, WHO, and World Bank, WHO Statement on Cesarean Section Rates, WHO, Geneva, Switzerland, 2015.
[3] F. Bragg, D. A. Cromwell, L. C. Edozein et al., "Variation in rates of caesarean section among english NHS trusts after accounting for maternal and clinical risk: cross sectional study," BMJ, vol. 341, p. 5065, 2010.

[4] G. Ali and S. Salarilak, "Why do some pregnant women prefer caesarean delivery in first pregnancy?" Iranian Journal of Reproductive Medicine, vol. 11, no. 4, pp. 301-308, 2013.

[5] M. R. Torloni, A. P. Betrán, P. Montilla et al., "Do Italian women prefer cesarean section? results from a survey on mode of delivery preferences," BMC Pregnancy Childbirth, vol. 13 , no. 1 , p. $78,2013$.

[6] N. Fesseha, A. Getachew, M. Hiluf, Y. Gebrehiwot, and P. Bailey, "A national review of cesarean delivery in Ethiopia," International Journal of Gynecology \& Obstetrics, vol. 115, no. 1, pp. 106-111, 2011.

[7] S. Gebremedhin, "Trend and socio-demographic differentials of cesarean section rate in Addis Ababa, Ethiopia: analysis based on Ethiopia demographic and health surveys data," Reproductive Health, vol. 11, no. 1, p. 14, 2014.

[8] S. Ajeet and K. Nandkishore, "The boom in unnecessary caesarean surgeries is jeopardizing women's health," Health Care for Women International, vol. 34, no. 6, pp. 513-521, 2013.

[9] M. F. MacDorman, E. Declercq, F. Menacker, and M. H. Malloy, "Neonatal mortality for primary cesarean and vaginal births to low-risk women: application of an "intention-to-treat" model," Birth, vol. 35, no. 1, pp. 3-8, 2008.

[10] J. A. Lauer, A. P. Betrán, M. Merialdi, and W. Daniel, Determinants of Caesarean Section Rates in Developed Countries: Supply, Demand and Opportunities for Control, p. 29, World Health Report, Geneva, Switzerland, 2010.

[11] A. P. Betrán, J. Ye, A. B. Moller, J. Zhang, A. M. Gülmezoglu, and M. R. Torloni, "The increasing trend in caesarean section rates: global, regional and national estimates: 1990-2014," PLoS One, vol. 11, no. 2, Article ID e0148343, 2016.

[12] E. Soto-Vega, S. Casco, K. Chamizo, D. Flores-Hernández, V. Landini, and A. Guillén-Florez, "Rising trends of cesarean section worldwide: a systematic review," Obstetrics \& Gynecology International Journal, vol. 3, no. 2, 2015.

[13] M. F. MacDorman, F. Menacker, and E. Declercq, "Cesarean birth in the United States: epidemiology, trends, and outcomes," Clinics in Perinatology, vol. 35, no. 2, pp. 293-307, 2008.

[14] M. P. Corry, S. F. Delbanco, and H. D. Miller, "The cost of having a baby in the United States," Truven Health Analytics, Greenwood Village, CO, USA, 2013.

[15] E. Soto Vega, M. Urrutia-Osorio, A.-V. Fernando, B. I. Y. Lopez, and H. R. C. Hazel, "The epidemic of the cesarean section in private hospital in Puebla, México," $\mathrm{Ob}$ stetrics \& Gynecology International Journal, vol. 2, no. 6, pp. 184-187, 2015.

[16] M. Hafeez, A. Yasin, N. Badar, M. I. Pasha, N. Akram, and B. Gulzar, "Prevalence and indication of caesarean section in teaching hospital," JMSA, vol. 27, no. 1, 2014.

[17] M. S. Harrison, O. Pasha, S. Saleem et al., "Prospective study of maternal, fetal, and neonatal outcomes in the setting of cesarean section in low- and middle-income countries," Acta Obstetricia et Gynecologica Scandinavica, vol. 96, no. 4, 2017.

[18] Central Statistical Agency (Addis Ababa, Ethiopia) and DHS Program ICF Rockville, Ethiopian Demographic and Health Survey 2016. Addis Ababa, Ethiopia and Calverton, Central Statistical Agency and the DHS Program ICF Rockville, Rockville, Maryland, USA, 2016.

[19] Federal democratic republic of Ethiopia and Ministry of Health, Management Protocol on Selected Obstetrics Topic, 
pp. 160-167, Ministry of Health, Addids Ababa, Ethiopia, 2010.

[20] F. E. Abebe, A. W. Gebeyehu, A. N. Kidane, and G. A. Eyassu, "Factors leading to cesarean section delivery at felegehiwot referral hospital, northwest Ethiopia: a retrospective record review," Reproductive Health, vol. 13, no. 1, 2015.

[21] F. T. B. Mengistie, "Prevalence of caesarean section in urban health facilities and associated factors in eastern Ethiopia: hospital based cross sectional study," Journal of Pregnancy and Child Health, vol. 2, no. 3, 2015.

[22] A. Olanipekun, "Prevalence of cesarean section and associated factors in private hospitals in Addis Ababa," 2017.

[23] S. Wahdey, A. Bayray, and G. Fisseha, "Determinants of caesarean delivery in ayder referral hospital, Mekelle, Tigray, Ethiopia, a case control study," Research and Reviews: Journal of Medical Science and Technology, vol. 5, no. 1, pp. 52-59, 2016.

[24] A. G. Wondie, A. A. Zeleke, H. Yenus, and G. A. Tessema, "Cesarean delivery among women who gave birth in Dessie town hospitals, northeast Ethiopia, a retrospective study," PLoS ONE, vol. 14, no. 5, Article ID e0216344, 2019.

[25] M. M. Philémon, M. C. Julie, M. Ntakwinja, K. B. Célestin, and M. M. Théodore, "Factors associated with caesarean section at Bukavu provincial hospital in democratic republic of Congo," International Journal of Reproduction, Contraception, Obstetrics and Gynecology, vol. 6, no. 12, p. 5219, 2017.

[26] I. Al Busaidi, Y. Al-Farsi, S. Ganguly, and V. Gowri, "Obstetric and non-obstetric risk factors for cesarean section in Oman," Oman Medical Journal, vol. 27, no. 6, pp. 478-481, 2012.

[27] S. Kahsay, G. Berhe, A. Gebremariam, and B. Birhan, "Determinants of caesarean deliveries and its major indications in Adigrat hospital, northern Ethiopia a case control study," Epidemiology (Sunnyvale), vol. 5, p. 192, 2015. 